\title{
ANÁLSIS DE LA PINTURA CONTEMPORÁNEA ESPAÑOLA EN EL MERCADO DEL ARTE Y LAS SUBASTAS ${ }^{1}$

\author{
ANALYSIS OF CONTEMPORARY SPANISH PAINTING IN THE ART MARKET AND AUCTIONS SALES
}

\author{
Olga Robledano Menéndez \\ Universidad Rey Juan Carlos \\ ORCID: 0000-0002-2475-2368 \\ olgarobledano22@gmail.com
}

Ana Pilar Vico Belmonte

Universidad Rey Juan Carlos ORCID: 0000-0002-2043-888I ana.vico@urjc.es

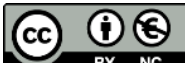

\section{Resumen |}

En este artículo se lleva a cabo un estudio sobre la rentabilidad de la pintura contemporánea española en relación con las ventas en subasta en la última década. Para ello, se han seleccionado veinte artistas españoles de la segunda mitad del siglo XX, en virtud del volumen de negocio generado dentro del mercado del arte a nivel nacional e internacional, y se han analizado tanto sus obras como los métodos de venta y las plazas en las que se realizaron de forma que, a partir de los datos pudiéramos extraer reflexiones sobre sus rentabilidades, tendencias coleccionistas y cifra de negocios del sector en estos años. Entre los resultados de la investigación se han reflejado las diferentes circunstancias de la pintura de los artistas nacionales en subasta, así como la trascendencia cultural y económica de estos, en el mercado internacional y nacional. Demostrando cómo el sector del arte contemporáneo que en los últimos años se vislumbraba como uno de los periodos más demandados por los coleccionistas, durante los periodos de recesión económica parece retraerse, en pro de la pintura de periodos anteriores o de artistas plenamente consolidados.

Palabras clave: Rentabilidad; Artistas españoles; Subastas; Inversión en arte; COVID-19.

\section{Abstract}

This paper carries out a study on the profitability of Spanish contemporary painting in relation to auction sales in the last decade. For this purpose, twenty Spanish artists from the second half of the twentieth century have been selected, by virtue of the volume of business generated within the art market at national and international level, and their works have been analyzed as well as the methods of sale and the places where they were made so that, from the data we could extract reflections on their profitability, collecting trends and turnover of the sector in these years. Among the results of this research, we have been able to identify the different circumstances of the painting of national artists at auction, as well as their cultural and economic transcendence in the international and national market. Demonstrating how the contemporary art sector, which in recent years was seen as one of the

${ }^{1}$ Recibido/Received: 22/09/2021

Aceptado/Accepted: 21/0I/2022

SHJ, 2022, 2(I), pp. 175-194. ISSN: 2792-3967 
most demanded periods by collectors, during periods of economic recession seems to retract, in favor of the painting of previous periods or fully consolidated artists.

Keywords: Profitability; Spanish artists; Auctions sales; Art investment; COVID-19.

\section{| Introducción |}

En estos últimos diez años y especialmente a partir de 2020, el mercado del arte nacional e internacional ha sido objeto de importantes cambios económicos y estructurales, los cuales han dado lugar a una nueva perspectiva de futuro para el sector. Su evolución, causas y consecuencias se han analizado y estudiado en múltiples ocasiones a lo largo de estos años (Vico y Villareal, coord., 2020). Sin embargo, encontramos aún un vacío en los estudios sobre la obra de artistas actuales y su irrupción en el mercado nacional de las subastas de arte, pues es importante entender que el mero hecho de trasladar su distribución del mercado primario al secundario supone una consolidación de la obra y el artista. Así pues, con este estudio queremos centrarnos en la evolución y rentabilidad que presenta la pintura contemporánea española vendida en subastas públicas durante la última década, a través de una escogida selección de artistas en virtud de sus resultados de ventas, donde se analizará pormenorizadamente su progreso en el mercado de la pintura tanto global como nacional desde el 2010 hasta nuestros días, en las ventas por subasta.

El objeto de estudio de este artículo se centra, por tanto, en el análisis de las obras de arte contemporáneo creadas dentro del mercado del arte español y ofertada en los últimos años. Los objetivos específicos del estudio tratan de justificar cómo la rentabilidad presentada por la selección de artistas aquí estudiados ha permitido su incorporación al mercado secundario y su consolidación en él, reconociendo cómo las preferencias coleccionistas han llegado incluso a marcar con su demanda, las especialidades de los artistas. Demostrando así que la creación artística viene muy determinada por la demanda global del mercado del arte.

Partimos de la premisa que el mercado primario, conformado por las galerías de arte contemporáneo, es el primer contexto comercial en el que se inserta la obra de reciente creación de artistas emergentes y coetáneos. Un entorno que tal y como definen Leggio y Gracia (Leggio y Gracia, 2020) se centra en un contexto dinámico de oferta, en el que los artistas suelen encontrar dificultades para entrar y consolidarse. Teniendo en el mercado secundario, conformado por casas de subastas e intermediarios, su objetivo a cumplir a largo plazo, por contar con una demanda forjada a partir la generalización de la demanda de su obra y la competencia de los coleccionistas (Reviriego, 2015) lo que equilibra su consolidación en los casos de éxito y determina el final de carreras artistas si la demanda se pierde, pues ya la relación artista-galería.

A pesar de lo anterior, el mercado del arte contemporáneo español cuenta con un grupo de artistas muy cotizado y estudiado por su alta calidad. De hecho, desde la perspectiva del mercado del arte observamos que en un plazo de diez años estas obras y, sobre todo sus autores, se han consolidado firmemente dentro del mercado secundario nacional e 
internacional, de tal forma que los remates de sus obras han alcanzado cifras comparables a las de otros artistas internacionales, aún si bien el mercado del arte español se mueve en un rango de precios inferior al internacional (Mc.Andrew, 2017). La presencia en el mercado secundario de estas obras supone haber superado el riesgo de no vender en subasta, el cual está íntimamente relacionado con un equilibrio de su demanda y sobre todo con la justificación de sus cotizaciones (Vico et al, 2016).

En este estudio se escogieron los remates alcanzados por veinte artistas españoles de renombrado prestigio, que en la última década han ido participando progresivamente con sus obras en las ventas por subasta, lo que supuso un espaldarazo a sus cotizaciones históricas, puesto que la venta por subasta como oferta objetiva que es, en la que los clientes fijan el precio a través de sus pujas (Vico et al., 2015), supone un paso en la consolidación y revalorización de estas obras en el mercado.

Así pues, partimos de una primera hipótesis centrada en demostrar la necesidad de la consolidación del volumen de demanda de los artistas para proceder a su venta por subasta, dato que vendrá demostrado por el incremento de las cotizaciones y su comparación histórica a través de los informes anuales (Deloitte, 2011-2020 y ArtPrice; 2011-2020) y repositorios virtuales. Lo que nos lleva a formular la segunda hipótesis sobre la rentabilidad de estas obras, derivada de su consolidada demanda. Asimismo, con este trabajo se pretende reconocer, por una parte, la trascendencia económica que ha tenido la obra de los artistas escogidos, no sólo en nuestro mercado nacional, sino también en el internacional, así como la relevancia que tienen esos artistas en el contexto comercial y la indudable trascendencia cultural que han dejado.

La pintura, es pues, el eje central de la investigación ya que es, por excelencia, la categoría artística más valorada en los últimos dos siglos de historia del mercado del arte. El procedimiento que se ha seguido para examinar la rentabilidad de las obras, ha sido mediante la comparación de la cifra de negocios del sector en sus ventas por subasta pública durante el periodo de tiempo citado (2010-2020), sobre una muestra de veinte artistas españoles contemporáneos previamente escogidos en virtud de unos criterios de representatividad, calidad, volumen de su cifra de negocio y demanda generada, prescindiendo de grandes maestros como Picasso o Dalí, en pro de reconocer el trabajo de otros artistas para no desvirtuar las cifras con sus abrumadores datos económicos.

El trabajo se ha estructurado en tres módulos. El primero de ellos analiza el contexto económico en el que el mercado del arte se ha visto involucrado durante la década analizada. A continuación, la investigación examina el comportamiento de la pintura española contemporánea dentro del mercado de las subastas. Para contextualizar dicho tema, se realiza un recorrido por la situación del mercado del arte español en la última década, analizando en profundidad el mercado de la pintura en subasta de cuatro de los veinte artistas seleccionados, pues estos engloban a su vez, situaciones compartidas con los demás artistas. Finalmente, se ha querido atender a la compleja situación derivada de la crisis sanitaria provocada por la Covid-19 dentro del mercado del arte nacional e internacional. Para lo cual se han buscado y comparado paralelos con lo ocurrido en el mercado durante la crisis económica del 2008. Metodológicamente, debemos matizar 
que los datos que se manejan en este estudio han sido recogidos hasta mitad del año 2020, debiéndose tener en cuenta cuando se referencie este último.

\section{| Introducción al mercado del arte |}

El mercado de bienes artísticos y de colección comprende sectores de gran arraigo y antigüedad en la sociedad. Las piezas que actualmente encontramos insertas en su oferta, en las subastas, ferias, galerías y demás negocios del sector, son por lo general, obras que proceden de colecciones antiguas y que llevan dentro del circuito del mercado del arte décadas. Podría decirse que el grosso superior de piezas que lo componen, estaría formado por piezas de calidad media alta, de escasa rareza y con un interés comercial amplio. Estos bienes han sido puestos a la venta a través de la Historia desde tiempos remotos, teniendo referencia de esos mercados e incluso obras adquiridas a través de las fuentes clásicas (Vico, 2019 y Casado Rigalt, 2020).

Europa, como la cuna del mercado del arte que es, almacena en su historia la creación de las más antiguas colecciones. Colecciones que nacieron en dependencias reales y aristocráticas para pasar posteriormente a conformar los más prestigiosos repertorios museísticos, siendo así el sector privado quien tradicionalmente ha configurado las colecciones públicas de los grandes museos europeos actuales. Numerosas pruebas de todo ello las encontramos en la capital británica, pues son muchas las colecciones tanto del Victoria \& Albert Museum como del British Museum o de la National Gallery que ligan su integración a la institución por donaciones, cesiones o incluso ventas de coleccionistas privados. $Y$ es que es en Londres donde localizamos en momentos previos a la fundación de las instituciones museísticas, el establecimiento de las grandes casas de subastas de venta de arte y antigüedades; en 1666 se fundó Spink y medio siglo más tarde localizamos la creación de Sotheby's en 1744 y Christie's en 1766, demostrando el auge del mercado por una demanda constante de obras de arte, libros, muebles, joyas etc. Sin embargo, desde el siglo $X X$ fueron los grandes capitales norteamericanos los que trasladaron a su territorio las colecciones y adquisiciones más espectaculares, debido a su enorme capacidad de compra e interés por el desarrollo cultural de su sociedad y la creación de un patrimonio propio de calidad. Llegando a los albores del siglo XXI con una trayectoria en ascenso que le llevó a presentar en 2007 los resultados más extraordinarios en cuanto a ventas, principalmente de arte contemporáneo y de posguerra, tanto en número de obras como en precio.

El mercado de bienes artísticos y de colección ha crecido significativamente en las últimas décadas, incluso a pesar de las dos crisis económicas vividas en cada una de las décadas de lo que llevamos de siglo $X X I$, pero mucho mayor es su evolución si lo analizamos desde finales del tercer cuarto del siglo $X X$ cuando el mercado del arte comenzó a mostrarse como un entorno exclusivo de ventas muy apropiado para la inversión. Desde entonces son muchas las transformaciones mostradas que le han permitido adaptarse a las necesidades y exigencias de los coleccionistas a través de modas, avances tecnológicos y crisis de diversa naturaleza.

Deteniéndonos en el mercado español, encontramos que los precios han sido tradicionalmente más bajos que en el mercado internacional, ya que las motivaciones 
coleccionistas, las leyes de mecenazgo y la legislación de Patrimonio Histórico no favorecen ni propician el desarrollo del coleccionismo. Nuestra legislación de Protección de Patrimonio Histórico es de marcada tendencia proteccionista lo que no ha favorecido la intervención de clientes extranjeros dentro de él. A ello se añade que el coleccionismo español no se representa por un coleccionista de grandes estipendios que busque excelentes calidades, como el británico o el estadounidense, por lo que las piezas ofertadas dentro de nuestras fronteras no siempre han alcanzado extraordinaria rareza y calidad, manteniendo unos parámetros de precios por tanto más bajos.

Ante esto cabe una explicación más, las legislaciones proteccionistas en cuanto a Patrimonio Histórico hacen que las piezas autóctonas de los países con regulaciones más proteccionistas, apenas se hayan exportado y que por tanto se localicen más frecuentemente en mercados locales y reducidos, provocando diferencias importantes en cuanto a precios. Nos referimos con ello, a mercado geográficos, donde las leyes locales (generalmente de ámbito nacional) ejercen un férreo control sobre las exportaciones e influyen en el volumen de la oferta. Consecuencia de todo ello ha sido la tendencia de los propietarios de grandes obras a conseguir los permisos de exportación y venderlas en plazas extranjeras con mayor confluencia de demanda y logrando así mayor rentabilidad en sus ventas.

Sobre la inferencia de las motivaciones y tendencias coleccionistas en el mercado del arte, debemos atender que las piezas de baja calidad no tienen apenas mercado, al coleccionista no le suele interesar piezas poco atractivas y mal conservadas, incluso si la pieza ya ha sido tratada o restaurada y la degradación se ha neutralizado, una pieza excesivamente deteriorada, se considera una pieza poco estética y por tanto poco demandada. Sólo aquéllas que presentan alguna característica particular, relacionada con su rareza o con alguna anécdota histórica pueden resultar comercialmente interesantes. Pero la pauta natural es que apenas se encuentra mercado para las piezas de mínima calidad, por muy bajo que sea su precio.

En referencia a las características de las obras de arte, hemos de entender que una vez son ofertadas en el mercado la demanda se genera y motiva a partir de sus cualidades y particularidades. Así es como las piezas raras son consideradas como tales, porque apenas se encuentran, ni en el mercado, ni en colecciones particulares o públicas. Las piezas raras de localizar son interesantes para coleccionistas avanzados y suelen servir como revulsivo de los precios cuando salen en venta al mercado. Paralelo al término de rareza encontramos el de escasez, que hace referencia a la presencia de ese tipo de bienes en el mercado. Es decir, podemos encontrar piezas que no son de gran rareza, sin embargo, su demanda es tan alta que en cuanto se oferta alguna la venta es casi inmediata. En esta segunda acepción, la escasa presencia del bien en el mercado no se debe a que no haya ejemplares, sino a que la demanda supera enormemente a la oferta, es decir la demanda de ese tipo de bien es mucho mayor que en otros similares. Además, en el mercado del arte existe una importante diversidad de productos (pintura, escultura, fotografía, mobiliario, etc.) más que en otros mercados, lo que provoca que cada bien tenga un comportamiento distinto en cuanto a su rendimiento. Ni siquiera dentro de un miso sector tienen la misma revalorización cuadros de autores y 
cronologías diferentes, cuanto menos aún porcelanas u otros objetos de las artes decorativas, lo que introduce más factores y más complejos a la inversión, que eso sí, a su vez facilitan la diversificación.

Como vemos, el mercado de bienes artísticos y de colección está muy condicionado a las tendencias de cada momento, que pueden depender de modas, exposiciones, efemérides... Artistas o movimientos que durante una época alcanzan precios altos pueden caer de manera considerable tiempo después, tanto en precios como en volumen de ventas, como ha ocurrido en los últimos años con los maestros ingleses. Esto le imprime al mercado una incertidumbre poco atractiva para los inversores, considerando al mercado, especialmente el contemporáneo, excesivamente arriesgado e imprevisible. Al analizar la rentabilidad de una obra de arte, destacamos la falta de liquidez, debido a la dificultad de venta inmediata de determinadas obras de gran coste y envergadura, que presentan además tan lenta revalorización.

Tras la crisis económica global iniciada a finales de la primera década de siglo XXI, la incertidumbre económica había dirigido las tendencias de compra hacia los bienes más antiguos y consolidados de cada sector. Ya que parecen representar un campo más seguro al tratarse de autores, objetos y precios a pagar plenamente conocidos $y$ afianzados en el mercado, debido a su constante y equilibrada demanda a lo largo del tiempo. Fue así como dentro de los mercados financieros llegó a crearse una sección en la que el arte ocupaba su propio espacio con las denominadas: Passion investment, que además de un retorno financiero, proporcionan a su vez un retorno emocional. Dentro de este tipo de inversiones el arte representa el 25\% del total. Según el informe Art Market Trends (ArtPrice, 2020), las ventas totales de arte y antigüedades alcanzaron los 64.000 millones de euros en el año 2019, mostrando una tendencia positiva en la última década, incluso superando más rápidamente que otros sectores la crisis económica originada en 2008 y tal y como veremos en estas líneas, solventando las dificultades provocadas por la crisis sanitaria de 2020 gracias a su eficacia en la digitalización mayoritaria de sus canales de venta.

Estas razones nos llevan a estudiar el mercado del arte y todos los bienes artísticos y de colección que dentro de él se ofertan, como adquisiciones eficientes atendiendo eso sí, a ciertas particularidades de apreciación estética y rentabilidad en las ventas posteriores. Siendo reconocidos con esa nomenclatura de Passion Investments por los sectores más económicos del arte. Presentando un mercado que cada día se ha visto más fortalecido por las continuamente crecientes posibilidades de adquisición de bienes que en algunos sectores han presentado comportamientos muy similares a los de productos financieros, de tal forma que se han llegado a desarrollar fondos de inversión con ellos. Es así como el arte también se ha revelado como una inversión de futuro que, a pesar de las dificultades económicas actuales, continúa apreciándose como un valor en alza (Vico y Sánchez Vasconcellos, 2021). El arte como inversión presenta unas características muy particulares que hay que tener muy en cuenta. Ya que las obras de arte son únicas y no puede ser reemplazadas por otras pues nada tienen que ver en precio, demanda, técnica, temáticas las diferentes autorías, mientras que al comprar acciones de una empresa no se especifica la acción particular que se adquiere." Esto condiciona el precio de una obra 
de arte de manera fundamental, ya que, en ocasiones, el propio nombre del artista lleva aparejado un rango de precios sólo a su autoría, aunque bien es cierto también que dentro de la obra del autor cada época cotiza de una manera distinta pues es la calidad artística lo que acumula el mayor peso ponderable en la carga del precio. La obra de arte original y única es lo que los inversores en arte compran al especular en el sector, y es esa rareza lo que justifica el alto precio (Baltayan, 2020).

\section{| Contexto del mercado de la pintura contemporánea en la última década |}

Si por algo se caracterizó el mercado del arte global y nacional en los últimos años, fue por la necesidad de recuperación de la crisis financiera de 2008. Su rápida mejoría vino dada, sobre todo, por un cambio en la demanda, ya que los coleccionistas mostraron cierto agotamiento debido a burbujas de precios irreales para ciertas obras de arte que no resistieron la prueba del tiempo. Es por ello por lo que, las casas de subastas se vieron en la necesidad de adaptar la oferta al contexto económico, considerando así la compra de lotes más asequibles como grabados y dibujos, que no pararon de venderse debido principalmente, a sus precios más accesibles.

A la hora de analizar la situación de un sector económico y las perspectivas futuras de sus empresas en momentos de inestabilidad o recesión, resulta fundamental atender a la situación en la que se encontraba en el momento anterior. El mercado del arte, al igual que el resto de los sectores económicos, se vio muy afectado por la crisis económica, los datos de bonanza vividos en 2007 no han vuelto aún a los mismos niveles. $\mathrm{Si}$ bien es cierto que no todos los sectores del arte sufrieron el mismo impacto ni tampoco durante el mismo plazo de tiempo. Aunque la salida de la crisis fue relativamente temprana, sobre todo comparado con el resto de las industrias culturales y creativas, la venta de las obras de arte y los bienes de colección quedó muy afectado por la crisis financiera de 2008 arrastrando datos regresivos en los precios de venta las obras arte, sobre todo para el sector del arte contemporáneo. De hecho, tal y como demuestran los datos del repositorio digital francés Artprice (https://es.artprice.com/), al comienzo de la crisis las ventas de arte antiguo crecieron entre un $6,8 \%$ y un $12,5 \%$ de volumen de negocio en todo el mundo, mientras el arte moderno pasó de representar un 44\% a un 48\%; y el arte contemporáneo, más asociado a la especulación, vivió una retracción aproximada entre un $16 \%$ a un $10 \%$ según sectores y países. Al mismo tiempo, las casas de subastas también debieron adaptarse a la situación tornando sus ventas más selectas en cuanto a la oferta del número de lotes y calidad de estos.

Fue así como se logró controlar la caída de precios ajustando la oferta al volumen de la demanda de forma que el propio sistema permitió controlar el equilibrio y mostrar los bienes artísticos y de colección como un producto susceptible para la inversión. El mercado se autoajustó para mantener un buen ritmo de ventas y los precios al alza, lo que ha dado la idea generalizada que el mercado del arte parece ser más dependiente de los aspectos legislativos, que de la coyuntura económica externa. 
Asimismo, se produjo un cambio en la estructura del mercado, con una renovación no tanto de la oferta como de los canales de venta en virtud de los avances tecnológicos proporcionados y el crecimiento de las plataformas de compraventa de arte por internet, aumentando la competitividad de las ferias de arte por su amplia oferta y la importancia que cobraron a partir de entonces tanto los inversores como los fondos de inversión. Al mismo tiempo la recuperación y desarrollo del mercado artístico, vino dada por la expansión geográfica hacia Oriente, en la que China se convirtió en la primera plaza en ventas de obras en subasta, con una economía emergente y un constante incremento de inversores en cultura y su creación artística nacional, lo que desató el surgimiento de nuevos artistas emergentes.

De esta forma se alcanzó una paulatina estabilidad del mercado del arte global y el crecimiento del arte contemporáneo, a merced de un incremento en el volumen de transacciones y el número de obras ofertadas en ventas públicas en todo el mundo, diversificando entre las variadas opciones que los sectores del arte permiten; obra gráfica, acuarela, dibujo, etc. Todo ello conformó una interesante oferta para los grandes compradores asiáticos y de Oriente Medio, que entonces construían su industria museística, así como a la consolidación del arte contemporáneo como una alternativa de inversión. La llegada de grandes y numerosos coleccionistas de países emergentes supuso el revulsivo que buscaba el mercado del arte para salir de la situación de recesión.

Es así como asistimos a la entrada en el mercado del arte de los conocidos como países BRIC (Brasil, Rusia, India y China) y las consecuencias de su entrada supuso el fin de la crisis económica que, si bien provocó que el mercado del arte europeo sufriera una gran disminución del número de adquisiciones por parte de sus coleccionistas y transacciones realizadas por los marchantes europeos, en favor de los coleccionistas y marchantes procedentes de los países BRIC. Estas economías en pleno desarrollo habían generado nuevos sectores poblacionales de alto nivel adquisitivo que comenzaron a interactuar profusamente en el mercado del arte.

El mercado del arte hasta la fecha ha contado con la ventaja de un sistema de ventas fuertemente consolidado que, en el caso de las subastas, muestra incluso cómo los precios son objetivamente justos en tanto que vienen dados por la relación directa entre la oferta y la demanda de los bienes ofertados. Si a ello le unimos que el mercado del arte se encuadra dentro del mercado de bienes de lujo y que sus compradores, por lo general, sufren menos las inestabilidades económicas, nos encontraremos con una situación relativamente generosa para el sector, incluso en los momentos de incertidumbre y recesión económica.

Por su parte, el mercado español experimentó casi coetáneamente los mismos factores de recuperación que el mercado internacional. Pero nuestra situación fue diferente, en primer lugar, porque algunos sectores se encontraban ante una crisis de producto previa a la crisis económica, y en esos casos, aunque la evolución fue a mejor, no salvó al sector de ello. A ello debemos añadir que nuestro mercado artístico es pequeño y, se enfrenta a ciertas circunstancias que limitan y dificultan su crecimiento desde hace años, como la falta de apoyo institucional, las escasas inversiones que hacen los coleccionistas en compras dentro de su país, la necesidad de internacionalizar más nuestro sector de cara 
a propiciar la carrera de nuestros artistas, o la de aumentar la credibilidad del sector, sobre todo respecto a la transparencia online.

A pesar de ello, el mercado nacional español pudo ajustarse al nuevo contexto económico y a las necesidades de los nuevos compradores. De hecho, aunque su recuperación fue más tardía que el mercado global, sigue siendo un mercado en crecimiento que, aunque ralentizado, continúa en creciente y dinámico desarrollo.

Dentro del mercado de arte contemporáneo las diferencias no son tan grandes pues la legislación resulta más laxa. Aun así, resulta incomprensible para muchos especialistas del sector, las enormes diferencias entre los estándares de precios que encontramos en el mercado del arte contemporáneo y en el mercado de arte antiguo. Sobre ello destacaremos que, a lo largo de la Historia, adquirir obras del mercado del arte contemporáneo ha sido, en términos generales, más dispendioso que el antiguo. De hecho, haciendo una comparativa de los datos actuales de precios y volumen de negocio encontramos que en España la venta de pintura contemporánea representa un 33\% del total con un volumen de negocio del $39 \%$ y un precio medio de la obra de $5190 €$. Mientras que, en el mercado internacional del arte, las ventas de obras de pintura contemporánea suponen el $46 \%$ del total, con un volumen de negocio del $44 \%$ y una media en el precio final de las obras de $34.645 €$, lo que desde luego supone una diferencia abrumadora en la potencial rentabilidad que las ventas pueden reportar a sus propietarios.

Esta lectura de los datos económicos del mercado del arte y la comparativa de cifras del sector en España respecto al mercado global, nos permite apreciar cómo tanto el valor como el volumen de ventas es mucho menor en nuestro país que respecto al resto del mundo, pero lo más significativo es el precio medio, ya que el precio medio global del arte contemporáneo en 2013 fue de 34.645€ frente al español con 5.190€. Este es un claro índice de la situación del mercado español, pues esta diferencia no sólo se da en los sectores aquí analizados, sino que es una tónica que se produce en casi todos los sectores del mercado del arte español al compararlos con los internacionales (Mc. Andrew, 2016).

Sin embargo, conviene recordar que sin demanda los precios no tienen fundamento, por lo que cada sector mantiene la oferta en las cotas que su mercado y la naturaleza de sus clientes puede abordar. Es cierto que la valoración de una obra contemporánea se realiza en base a unos factores menos justificables, que en el caso de las piezas antiguas no sólo cuentan con unos precios consolidados en el mercado, sino que son precios que vienen avalados por la propia clientela que a lo largo del tiempo ha demandado esas obras y la ratifican en las subastas a través de pujas, que de forma objetiva fijan sus precios.

\section{| Selección de artistas y análisis de su participación en el mercado de la pintura contemporánea española |}

Durante la crisis económica las preferencias coleccionistas se habían centrado en la obra artistas consolidados cuya compra no suponía un riesgo de devaluación sobre los precios 
pagados y ello supuso un retorno de los precios con extraordinarias subidas en las ventas por subasta. Continuando con esta pauta y tratando de mostrar mayores garantías en las adquisiciones, el sector del arte contemporáneo emuló esta línea de actuación y se centró en la venta de piezas de los artistas más consolidados y reconocidos a nivel internacional como Chillida, Zóbel, Valdés, Tápies, Barceló y Saura, que avalaban su posición por ser los más cotizados, por ingresos de ventas en subastas internacionales y nacionales, así como los más frecuentes en los catálogos de subastas y ferias, alternándose continuamente sus nombres en las subastas temporada tras temporada.

Ha sido justamente a partir de esta razón por la que se han seleccionado para nuestro estudio una veintena de artistas, entre los que figuran los más demandados, que representan seña de la identidad artística y cultural de nuestro país en la pintura de finales del siglo XX e inicios del XXI. Tal y como puede observarse en la siguiente tabla, presentamos el resultado del ranking de cotizaciones para, a continuación, exponer las diferentes particularidades de cada artista y su mercado.

Tal y como se aprecia en la tabla anterior se han situado a los artistas por orden de su media de cifra de negocio alcanzada a partir de las ventas de obras pictóricas, donde además podemos observar el número de lotes vendidos en esta misma categoría y de su obra completa, quedando así reflejada la rentabilidad de la pintura de cada artista. Por ejemplo, Miquel Barceló, situado en lo más alto de nuestra selección, vendió 103 lotes, frente a los 300 de Antoni Tàpies, quien sin embargo no alcanzó las cifras de remate de martillo cerradas por obras de Barceló. Es así como se observa que, aunque un artista venda menos lotes, los precios alcanzados pueden ser muy superiores y que por tanto su rentabilidad sea mayor. Lo cual guarda una lógica relación con la ley de la oferta y la demanda que resulta soberana también en el mercado del arte.

A lo largo del estudio de la obra de los artistas contemporáneos, se han observado pautas en la trayectoria de estos artistas que nos permiten sintetizar el análisis centrándonos en la obra de cuatro de ellos, que representan las diferentes situaciones de mercado de todos. De forma que al englobar en conjuntos obtenemos una visión completa y conceptualizada. En el elenco mostrado en la tabla 2 encontramos artistas cuya obra no se restringe a la pintura exclusivamente y de hecho pueden ser más demandados por su obra en otros soportes o técnicas, sin embargos su importancia en el mercado hace que los precios que alcancen se vean influenciados por esta situación.

Así pues, tras el análisis de los artistas seleccionados a partir de la rentabilidad generada tras la venta de su obra pictórica localizamos cinco grupos fundamentales; un primer grupo de artistas selectos entre los que se encuentran Miquel Barceló, Antoni Tàpies, Manolo Valdés, Fernando Zóbel, Antonio Saura y Manolo Millares, que cuentan con mayor proyección internacional, principalmente en Reino Unido y por ello cotizan a precios más altos. Un segundo grupo compuesto por Eduardo Chillida y Jaume Plensa,con una demanda centrada en la obra escultura, en vez de pintura, lo que identifica su carrera artística. El tercer grupo corresponde a los tres únicos artistas; Luis Feito, José María Sicilia y Albert Ràfols-Casamada cuya categoría más vendida es la pintura y con precios, más bajos que los de los artistas selectos, pues vienen determinados por las diferentes plazas de su mercado. José María Sicilia, Eusebio Sempere y Josep 
Guinovart protagonizan el cuarto grupo como artistas con los precios más bajos en su pintura, debido a que la totalidad de su mercado está en España. Finalmente, el quinto grupo, con Antoni Clavé, Eduardo Arroyo, Rafael Canogar, Manuel Hernández-Mompó, Luis Gordillo y Jorge Castillo, centran sus ventas más en obra gráfica que pintura y su puesto en el ranking depende de dónde se sitúe su nicho de mercado.

Buscando justificar estas posiciones se han analizado los grupos pormenorizadamente atendiendo a los lugares de venta y los precios de remate de las obras. De esta forma podemos distinguir en primer lugar la relevancia que adquiere el lugar en el que se produce la venta y en segunda opción el número de lotes y la técnica por la que el artista obtuvo su prestigio artístico tal y como se explicará en las páginas contiguas.

En primer lugar, se sitúa Miquel Barceló por ser el artista que mayor volumen de negocio ha generado en el periodo seleccionado para este estudio. Siendo su mejor año de ventas 2011, cuando consiguió su remate más alto con Faena de muleta, rematada en casi cuatro millones de euros. Asimismo, fue el año que más lotes de pintura vendió, un total de diecisiete. Datos que no logró mantener presentando una caída de precios hasta que en 2017logró remontar la situación principalmente a otro remate de casi tres millones de euros.

En general, el artista mallorquín vende más grabado que pintura, pero esta última supone un $95 \%$ de su cifra de negocios, ya que logra situar el precio final de venta entre los 100.000-500.000€ en subasta. Actualmente, su nicho de mercado se sitúa sobre todo en Reino Unido, lo que justifica los precios alcanzados ya que es un mercado donde los parámetros de precios son considerablemente más altos.

Tal y como se aprecia en el gráfico 1, la comparación de los ingresos medios anuales de Barceló con la del resto de artistas seleccionados, Barceló supera ampliamente, una media, que resulta baja, teniendo en cuenta los resultados del resto de artistas que no generan cantidades tan elevadas, ya sea por menor reconocimiento internacional y frecuencia en subasta. El análisis global de la obra de Barceló puede representar el comportamiento que presenta la obra de un grupo de artistas selectos compuesto por Antoni Tàpies, Manolo Valdés, Fernando Zóbel, Antonio Saura y Manolo Millares. Los cuales participan con frecuencia en subasta, pero sobre todo mantiene una gran proyección internacional, ya que el mercado de todos ellos se sitúa mayoritariamente en Reino Unido, capital del mercado del arte europeo.

Continuando con el análisis de las obras incorporamos los resultados obtenidos por Eduardo Chillida quien siempre ha mantenido una alta demanda por su obra escultórica, mayor que la percibida con el soporte pictórico. De hecho, habiendo vendido la escasa cifra de doce lotes de pintura en diez años, queda relegado al puesto décimo manteniendo una cotización entre 100.000-500.000€, en los últimos años. Sin embargo, a través de subasta sólo se ha registrado un lote vendido en 2019 tal y como puede apreciarse en el gráfico 2. Hemos de destacar que todos aquellos que se han ofertado en la década, han encontrado comprador, situando su oferta principalmente en Reino Unido, en España sólo ha vendido un lote de pintura en 2011. 
Estos datos son comparables con los presentados por Jaume Plensa, otro artista que alcanza mayores cifras con la venta de su obra escultórica. Es por ello por lo que en el repertorio de artistas seleccionados aparece antepenúltimo, ya que su pintura, aun habiendo vendido el doble de lotes que Chillida, tiene precios más bajos que el artista vasco, vendiendo sus obras entre los $10.000-50.000 €$. La razón de todo de todo ello puede situarse en que nos encontramos ante un artista con una demanda eminentemente nacional, donde los precios comparados con Reino Unido son más bajos.

El siguiente artista seleccionado del elenco es José María Sicilia quien se sitúa en puestos intermedios junto con Luis Feito y Albert Ràfols-Casamada. Los tres representan los únicos artistas de la clasificación cuya categoría más vendida es la pintura, a diferencia de los demás que venden más grabado, dibujo o escultura.

A partir del análisis de los datos se podría deducir que, al vender más pintura deberían obtener cifras de negocios más altas, ya que es la categoría técnica que mayores precios alcanza en subasta. Sin embargo, tal y como se aprecia en la tabla no es así, siendo su interpretación debido a que su mercado se sitúa principalmente dentro de nuestras fronteras. De hecho, Luis Feito, octavo en el ranking presenta mejor posicionamiento que Plensa ya su obra ofertada con mayor asiduidad es pictórica, incluso aquí en España y donde además vende obra gráfica. Pero principalmente situamos su mercado en Reino Unido, por lo que sus precios llegan incluso a alcanzar los $50.000 €$.

Sin embargo, en el caso de José María Sicilia, su mercado es principalmente español, sin menoscabo que también haya vendido obra en Reino Unido, pero entendemos que es lo que justifica que sus precios, expresados en el gráfico 3, alcancen de media los $10.000 €$, y por eso aparece prácticamente a mitad del ranking generado en este estudio. Frente a ello, encontramos las cotizaciones alcanzadas por la venta de las obras de Albert Ràfols-Casamada, en los puestos más bajos de la clasificación, cuyo mercado es casi en su totalidad español y sus precios rondan mayoritariamente los 1.000-5.000€.

Como podemos comprobar, estamos ante tres artistas similares en cuanto a categoría más vendida, es decir, la pintura, pero con gran diferencia en su cifra de negocios, en virtud de la diferencia de precios por la distribución geográfica de su mercado.

Finalmente, nos centramos en un último grupo, representado por Eusebio Sempere, cuyos datos tenemos expresados en el gráfico 4. Este artista se sitúa en el último puesto de nuestra selección por rentabilidades y representa, junto con Josep Guinovart los menores volúmenes de negocio, debido básicamente a que su mercado es casi exclusivamente español. Resulta sorprendente que Sempere presente prácticamente el mismo número de lotes vendidos de pintura que Pablo Palazuelo, quien aparece en el puesto número trece, pero este último encuentra demanda a su obra en Reino Unido y Francia, los que provoca un alza en sus precios rondan los 50.000-100.000€ y los de Sempere 5.000-10.000€, una diferencia más que notable.

Por su parte, Josep Guinovart, aunque haya vendido hasta cincuenta y nueve lotes de pintura, una cifra más alta que algunos de los artistas con mayor volumen de negocio, sus precios son aún bajos cifrándose entre los 5.000-10.000€. 


\section{| Situación actual del mercado del arte |}

A la hora de analizar las crisis en relación con las posibilidades de su superación por un sector económico, influye extremadamente la forma en la que se entra en ellas. En el caso de nuestro país, en ambas crisis, tanto en la crisis económica de 2008 como en la generada por la pandemia mundial de 2020, asistimos a una entrada descontrolada, cuyos inicios en ambos casos se caracterizaron por situarse dentro de un ambiente de negación que en absoluto ayudó a crear medidas de control que pudieran paliar los efectos y, por tanto, las recuperaciones posteriores. Desde luego, si algo se debe destacar del 2020, es la crisis sanitaria provocada por el Covid-19, y el impacto que produjo en el desarrollo de las herramientas online que han experimentado las empresas del mercado del arte.

Todas las situaciones críticas obligan a tomar decisiones que acaban generando diversas consecuencias. Ante la crisis sanitaria generada por la Covid-19, las decisiones tomadas por la gran mayoría de los países confinando a su población obligó a los profesionales del arte a proporcionar al mercado nuevos métodos de venta, eminentemente caracterizados por situarse dentro de los entornos virtuales. De tal forma que el desarrollo del e-commerce y la adaptación masiva de las nuevas tecnologías en los entornos del mercado del arte, nos llevan a esperar que esos nuevos coleccionistas, de los que hemos hablado en páginas anteriores, podrían ser los que en esta ocasión se incorporasen al mercado y supusieran un nuevo nicho de población al que atender. Por lo que sería muy necesario que los comerciantes ajustaran la oferta a este nuevo perfil.

Las casas de subastas, nacionales e internacionales, consolidaron y generalizaron sus subastas online para adaptarse a la nueva realidad. Inicialmente como única vía de comunicación con el mercado y buscando golpes de efecto como la subasta ONE de Christie's celebrada en directo a nivel mundial y centrada en la obra de artistas del siglo $X X$. Sin embargo, las subastas online pronto se revelaron como medio de venta más rentable y efectivo, aportando un nuevo canal a las cifras de negocio que no cesaron, simplemente, se transformaron, racionalizaron y digitalizaron, como demuestran los datos de beneficios publicados por las casas nacionales e internacionales

Por otro lado, el sector del arte contemporáneo siempre por delante en el mercado del arte en el uso de las herramientas de marketing y la implantación de los avances tecnológicos se vio muy perjudicado de nuevo por la situación de inestabilidad, pero principalmente por su gran dependencia de la presencialidad en las ventas tanto en galería como en ferias comerciales. Recordando años de dificultades superadas con la crisis económica de 2008, pero que poco a poco han ido superando para situarse en posiciones más positivas.

Con esta situación sin precedentes, quedó patente la repercusión y trascendencia que tienen los recursos online en el mercado del arte; así como la importancia de los esfuerzos colaborativos entre entidades, que han sido cruciales para resistir ante esta nueva realidad. Ejemplo de ello, es el protagonismo alcanzado por galerías y artistas, partícipes de iniciativas y plataformas online destinadas a dar visibilidad a su trabajo, 
como Online Viewing Rooms o \#ArteResistencia. Este renovado contexto digital debe fomentarse y aumentar su visibilidad y funcionamiento, para aprovechar la oportunidad de atender un nuevo nicho de mercado como es el millenial, modernizando así el sector, y diversificando el producto.

Ante la única fórmula de venta posible durante el confinamiento por la crisis sanitaria, el e-commerce, el mercado ha mostrado una clara intención de modernización del sector con la adaptación de las nuevas tecnologías en sus fórmulas de venta. Siempre hemos atendido a internet como un contexto lleno de posibilidades, pero a la vez de muchos peligros. Entre las dificultades con las que se encontrará el mercado del arte en el entorno digital, encontraremos la falta de confianza y la necesidad de los coleccionistas de ver las piezas antes de comprarlas. Pero, al mismo tiempo, las Administraciones y, en especial, las españolas necesitarán adaptarse a esta nueva situación, al igual que las casas de subastas que deberán cambiar su visibilidad y funcionamiento. Por todo ello, queremos animar desde estas líneas a los profesionales y representantes de gremios a buscar fórmulas que fortalezcan el mercado en la línea de cómo se viene haciendo desde CINOA, international federation of art \& Antique dealer associations (https://www.cinoa.org/)

Finalizamos este estudio destacando la necesidad de analizar los efectos de la crisis financiera de 2008 para minimizar en lo posible los que la crisis sanitaria de 2020 pudiera tener en el mercado del arte. Es necesario volver a revisar las medidas tomadas para no repetir errores y sobre todo poder potenciar cualquier oportunidad de mejora que se presente. De hecho, en el caso español, la entrada descontrolada y carente de una dirección clara por parte de las Administraciones que marcasen una hoja de ruta, tiene como principal consecuencia la descoordinación y sensación de desamparo de los profesionales por parte de las autoridades que no han tomado, en ninguno de las dos crisis, decisiones en cuanto a protocolos de actuación que pudieran paliar los efectos de la crisis, o en cuanto a recomendaciones e incluso ayudas que pudieran dar a los profesionales un resquicio de esperanza ante una situación crítica. Todo ello nos lleva a repetir una reflexión realizada ya en estudios previos, sobre la necesidad que tiene el mercado de bienes artísticos y de colección español de proveerse de una estructura organizativa y comunicativa de los profesionales del mercado del arte que, de forma conjunta, represente todas aquéllas facetas en las que coinciden, independientemente del gremio al que pertenezcan y que, incluso, cuente con su propia asociación gremial, pero que debe unirse para alcanzar un quorum lo suficientemente representativo como para que las Administraciones atiendan un conjunto común de necesidades tanto en periodos de crisis como de bonanza (Vico, 2020).

\section{| Conclusiones |}

El análisis del mercado de subastas de artistas contemporáneos en la última década parece mostrarnos respuesta a la primera de las hipótesis aquí planteadas, que indica que las preferencias coleccionistas por obras de artistas consolidados ha dificultado la penetración en el mercado de artistas emergentes que, tras la sucesión de dos crisis económicas, en las dos décadas que llevamos de siglo XXI, se entronan como los grandes 
perjudicados de esta coyuntura económica. Y, cuya única oportunidad de venta aparece cuando las piezas de artistas contemporáneos proceden a venderse en subasta, dejando así espacio en el mercado primario. Por su parte si el arte contemporáneo llega al mercado secundario es porque cuenta con un respaldo del público, que es quien puja por sus obras en las subastas y, por tanto, un mínimo de demanda, que avala cuanto menos el precio de salida de la obra.

Con este trabajo, queda reflejado cómo el mercado del arte consiguió recuperarse de una de las peores crisis financieras conocidas como fue la del 2008, gracias a ciertos cambios estructurales y económicos; así como las carencias del mercado español respecto al internacional. Por ello, las subastas se tornaron más selectas y propiciaron los lotes más demandados por los coleccionistas remanentes. En la actualidad el mismo los profesionales del mercado del arte trabajan para crear su propia salida estructural de la crisis generada por la pandemia de la Covid-19, atendiendo a las referencias dadas por la experiencia anterior. Particularmente, nuestra pintura contemporánea ha continuado generando gran volumen de negocio, sobre todo los artistas incorporados en el primer conjunto de nuestro estudio, quienes su grado de consolidación en los momentos de la llegada de las crisis les permitió mantener sus cotas de demanda o incluso incrementarlas.

Por su parte, la obra gráfica, se ha revelado como una de las soluciones para mantener el nivel de las ventas, máxime en España, pues con ello se adquieren obras originales de artistas de renombre, pero dadas las características intrínsecas de la producción de la obra gráfica, los precios resultan mucho más asequibles.

Por lo que se refiere a los precios de los remates, en España la horquilla de precio queda en unos niveles medio $o$ incluso bajos frente a los registrados en los mercados internacionales, debido a la menor capacidad de compra del coleccionista español, lo que incrementa la demanda de técnicas más accesibles. Debiendo destacarse como conclusión principal a la segunda hipótesis que la mayor o menor cifra de negocio generada por la venta de la obra de nuestros artistas viene dada por la distribución geográfica de su mercado.

En el contexto actual, los profesionales han sabido hacer frente a la situación gracias a las soluciones digitales, que han consolidado más aún la globalización del mercado y ha supuesto un empuje en la promoción de artistas e incorporación de nuevos coleccionistas.

Finalmente, a lo largo del análisis de la obra de los artistas, hemos visto cómo la demanda coleccionista ha fomentado la deriva de la creatividad artística a diferentes técnicas y soportes. Dentro del mercado internacional del arte donde los artistas han generado un producto del que su marca es el principal atractivo de su producto, los artistas suelen encontrar compradores para todo tipo de creaciones, sean de mayor o menor calidad (si es que este concepto tiene cabida dentro del denominado arte conceptual) pues la demanda se dirige principalmente hacia la marca que ese artista y su obra representan. Por lo que la libertad creativa del artista es mayor. Sin embargo, tal y como se ha visto en este estudio, cuando no atendemos a obras de artistas de demanda tan alta, la 
dependencia que tienen hacia las motivaciones de compra y tendencias de los coleccionista o compradores es mucho mayor y por tanto el artista favorece en su creación ese tipo de inspiraciones y labores artísticas.

\section{Referencias}

ARTPRICE. (2009). Informe del Mercado del Arte en 2009. Saint-Romain-au-Mont-d'Or: Thierry Ehrmann.

ARTPRICE. (2010). Informe del Mercado del arte en 2010. Saint-Romain-au-Mont-d'Or: Thierry Ehrmann.

ARTPRICE. (2011). Informe del Mercado del Arte en 2011. Saint-Romain-au-Mont-d'Or: Thierry Ehrmann.

ARTPRICE. (2012). Informe del Mercado del Arte en 2012. Saint-Romain-au-Montd'Or: Thyerry Erhmann.

ARTPRICE. (2013). Informe del Mercado del Arte en 2013. Saint-Romain-au-Montd'Or: Thyerry Ehrmann.

ARTPRICE. (2014). Informe del Mercado del Arte en 2014. Saint-Romain-au-Montd'Or: Thyerry Erhmann.

ARTPRICE. (2015). Informe del Mercado del Arte en 2015. Saint-Romain-au-Montd'Or: Thyerry Ehrmann.

ARTPRICE. (2016). Informe del Mercado del Arte en 2016. Saint-Romain-au-Montd'Or: Thyerry Erhmann.

ARTPRICE. (2017). Informe del Mercado del Arte en 2017. Saint-Romain-au-Montd'Or: Thyerry Ehrmann.

ARTPRICE. (2018). Informe del Mercado del Arte en 2018. Saint-Romain-au-Montd'Or: Thy erry Ehrmann.

ARTPRICE. (2019). Informe del Mercado del Arte en 2019. Saint-Romain-au-Montd'Or: Thyerry Ehrmann.

ART-TACTIC (2015). «The Hiscox Online Art Trade Report 2015». ArtTactic.

Consultado en http:// www.arttactic.com/market-analysis/art-markets/us-a-europeanart-market/699-hiscox-online-art-trade-report-2015.html

Baltayan, (2020). Art Investment; https://www.moneycrashers.com/art-investmen

Baumol, W.J. (1986). "Unnatural Value. Or art investment as a floating crap game". American Economic Review. Pp.: 10-14. 1986.

Casado Rigalt, D. (2020) "EL coleccionismo desde la prehistoria hasta el siglo XVI: entre la motivación religiosa, el deleite artístico, los códigos de exhibición y el negocio" $L a$ Albolafia: Revista de Cultura y Antigüedades, 20. Dossier: Estudios sobre el mercado del 
arte, presente y futuro en un contexto crítico (Coords. VICO \& VILLARREAL). Pp. 1335 .

CITI, 2020. "The global art market and COVID-19". Ed. Citi GPS: Global Perspectives \& Solutions. Revisable en: https://www.privatebank.citibank.com/ivc/docs/Citi-GPS-Artreport-Dec2020.pdf

Czujack, C. (1997). "Picasso Paintings at Auction, 1963-1994". Journal of Cultural Economics, 21. Amsterdam. Pp.: 229-247.

DELOITTE, Art \& Finance Report 2011-2019. Global Art \& Finance Ed. Luxemburgo

Leggio, A. y Gracia, M. (2020). "Arte emergente sincronismos entre universidad y mercado primario.". La Albolafia: Revista de humanidades y cultura, 20 "El mercado del arte en tiempos de crisis" Coords. Vico y Villarreal. Madrid.

Frey, B. y Pommerehne, W. (1989) "Art investments: An empirical inquiry”. Southern Economic Journal, 56 (2), Nueva Orleans. Pp.: 396-409.

Grampp, W. (1991). Arte, Inversión y Mecenazgo. Editorial Ariel. Barcelona.

Mc. Andrew, C. (2012). El mercado español del arte en 2012. Barcelona: Fundación Bancaria La Caixa (Fundación Arte y Mecenazgo).

Mc. Andrew, C. (2014). El mercado español del arte en 2014. Barcelona: Fundación Bancaria La Caixa (Fundación Arte y Mecenazgo).

Mc. andrew, C. (2017). El mercado español del arte en 2017. Barcelona: Fundación Bancaria La Caixa (Fundación Arte y Mecenazgo).

Reviriego, C. (2015). El laberinto del arte. El mercado del arte, su funcionamiento, sus reglas y sus principales figuras. Madrid: Grupo Planeta.

Rodríguez, J.M. (1998). Historia del arte contemporáneo en España e Iberoamérica. Madrid.

Ruiz López, J. I. (2007). "Introducción al mercado del arte en España". Actas de los XVII Cursos Monográficos sobre el Patrimonio Histórico, $n^{\circ} 11$. Reinosa.

Throsby, D. (1994) “The Production and Consumption of the Arts". Journal of Economic Literature, $n^{\circ} X X X I I$. Pp.: 12-23.

Vico Belmonte, A. "Del mercado de antigüedades arqueológicas a la creación de los museos arqueológicos". Boletín de la Asociación de Amigos de la Arqueología, 49-50. Madrid. Pp.: 11-36.

Vico Belmonte, A. "El mercado del arte en tiempos de crisis". La Albolafia: Revista de humanidades y cultura, 20. Madrid. Pp.: 321-346.

Vico, A.; Laguna, P. Rosendo, V. (2011). "Nuevas perspectivas del mercado del arte tras la crisis y con la presencia de los países de economías emergentes". Los mercados del mañana: bases para su análisis hoy. ESIC. Valencia. 
Vico, A., Orden, C. de la, (2017). "Nuevas opciones de financiación en el mercado del arte" en XXXI AEDEM Annual Meeting. Madrid.

Vico, A., Palomo, J., Laguna, Mª P. (2016). Análisis de los métodos de distribución más rentables en el mercado de los bienes artísticos y de colección. Madrid.

Vico, A., Palomo, J., Laguna, Mª P. (2015). La rentabilidad de las obras de arte. Estudio de los entornos propicios para la venta de bienes artísticos y de colección. Madrid.

Vico, A., Villareal, P. (2020). "Estudios sobre el Mercado del Arte, presente y futuro en un contexto crítico". La Albolafia: Revista de humanidades y cultura. Madrid.

Wilkis, A. (2018). El poder de (e)valuar. La producción monetaria de jerarquías sociales, morales y estética en la sociedad contemporánea. Colombia.

Veblent, T. (1899). The Theory of the Leisure Class; an economic study of institutions. MacMillan, Nueva York.

\section{Anexos}

Tabla 1. Cifra de negocios y volumen de ventas de arte contemporáneo español (20102020).

\begin{tabular}{|c|c|c|c|c|}
\hline \multicolumn{2}{|r|}{ Artista } & \multirow{2}{*}{$\begin{array}{c}\text { Media de cifra de } \\
\text { negocios } \\
3.549 .663 €\end{array}$} & \multirow{2}{*}{$\begin{array}{c}\text { Lotes vendidos } \\
\text { pintura } \\
103\end{array}$} & \multirow{2}{*}{$\begin{array}{c}\begin{array}{c}\text { Total } \\
\text { vendidos }\end{array} \\
301 \\
\end{array}$} \\
\hline 1. & Miquel Barceló & & & \\
\hline 2. & Antoni Tàpies & $3.401 .924 €$ & 318 & 3.573 \\
\hline 3. & Manolo Valdés & $2.233 .084 €$ & 139 & 453 \\
\hline 4. & Fernando Zóbel & $1.969 .703 €$ & 194 & 533 \\
\hline 5. & Antonio Saura & $829.038 €$ & 156 & 769 \\
\hline 6. & Manolo Millares & $768.014 €$ & 51 & 158 \\
\hline 7. & Antoni Clavé & $333.884 €$ & 209 & 1.413 \\
\hline 8. & Luis Feito & $240.488 €$ & 210 & 375 \\
\hline 9. & Eduardo Arroyo & $137.621 €$ & 103 & 598 \\
\hline 10. & Eduardo Chillida & $104.659 €$ & 12 & 1.741 \\
\hline 11. & Rafael Canogar & $101.860 €$ & 102 & 364 \\
\hline 12. & José María Sicilia & $66.598 €$ & 80 & 159 \\
\hline 13. & Pablo Palazuelo & $64.634 €$ & 9 & 230 \\
\hline 14. & Manuel Hernández Mompó & $60.755 €$ & 42 & 198 \\
\hline 15. & Luis Gordillo & $40.588 €$ & 43 & 206 \\
\hline 16. & Jorge Castillo & $39.582 €$ & 145 & 489 \\
\hline 17. & Albert-Ràfols Casamada & $32.000 €$ & 77 & 200 \\
\hline 18. & Jaume Plensa & $23.181 €$ & 24 & 190 \\
\hline 19. & Josep Guinovart & $22.876 €$ & 59 & 272 \\
\hline 20. & Eusebio Sempere & $4.738 €$ & 6 & 188 \\
\hline
\end{tabular}

Fuente: Artprice (2020). 
Gráfico 1. Cifra de negocios de pintura de Miquel Barceló (2010-2020).

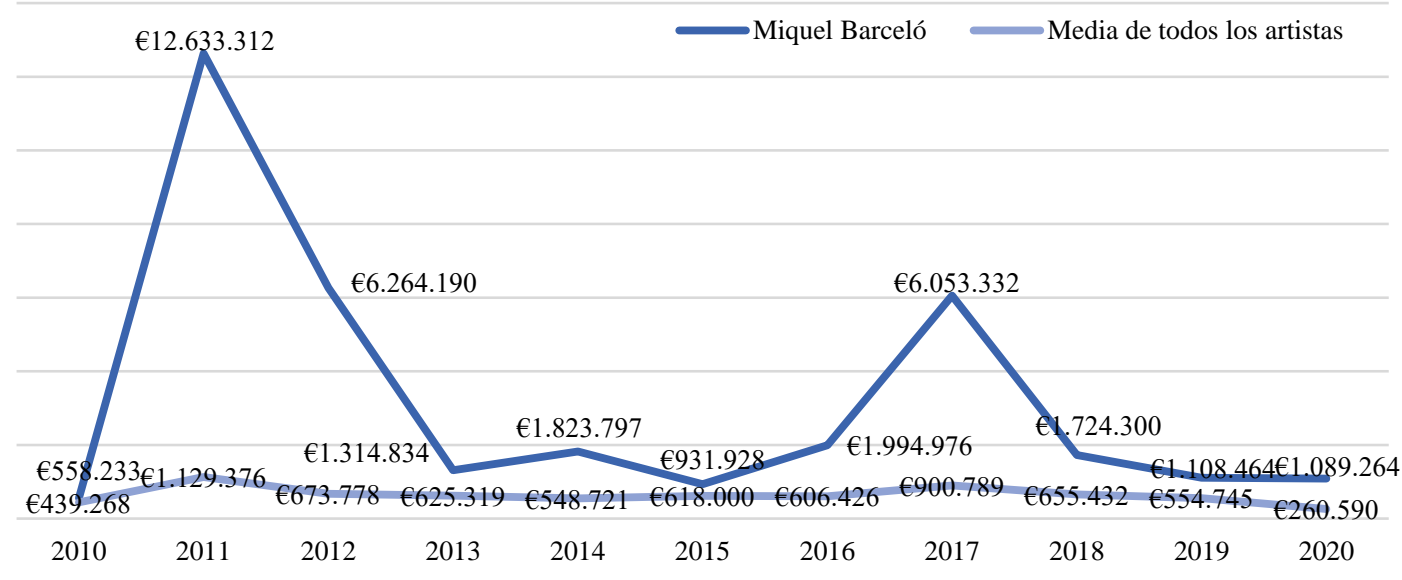

Fuente: Artprice (2020).

Gráfico 2. Cifra de negocios de pintura de Eduardo Chillida (2010-2020).

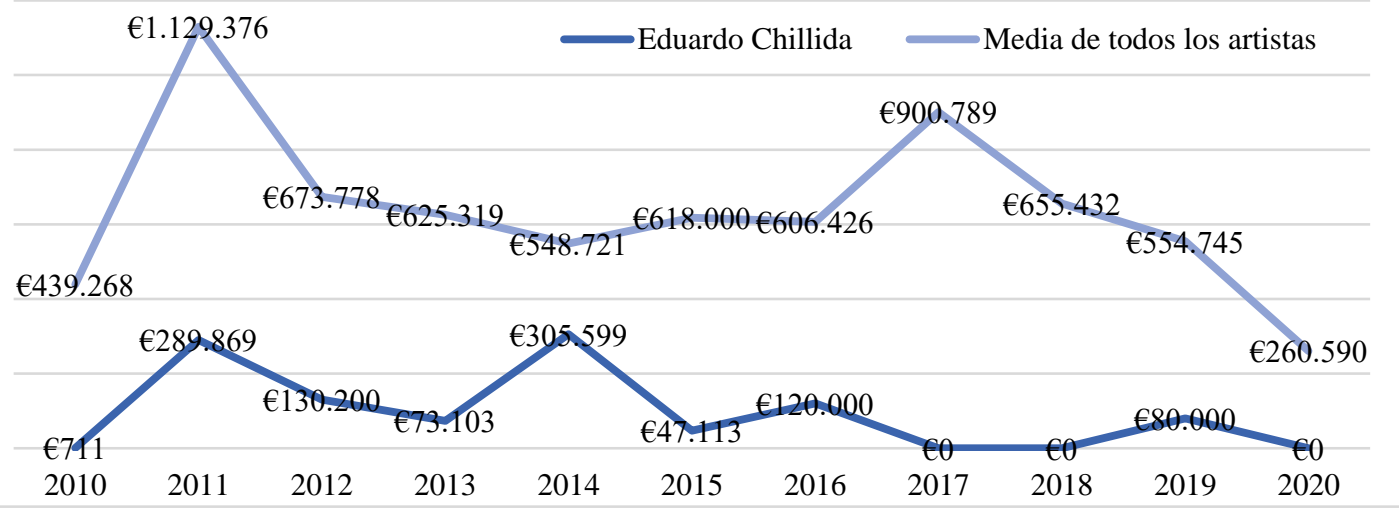

Fuente: Artprice (2020).

Gráfico 3. Cifra de negocios de pintura de José María Sicilia (2010-2020).

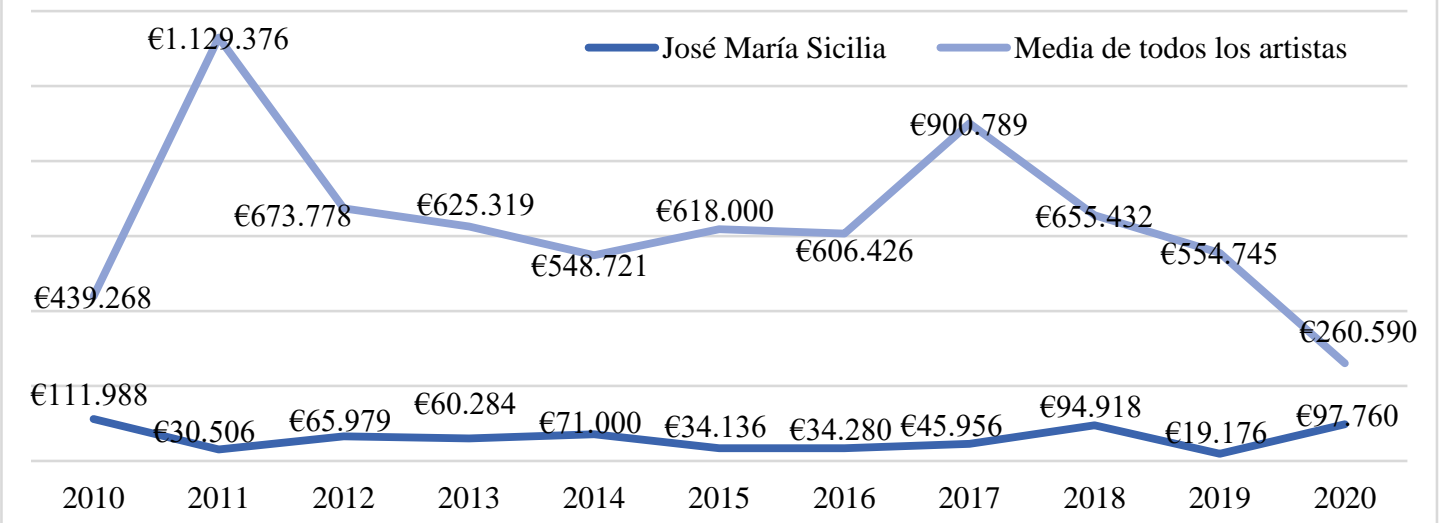

Fuente: Artprice (2020). 
Gráfico 4. Cifra de negocios de pintura de Eusebio Sempere (2010-2020).

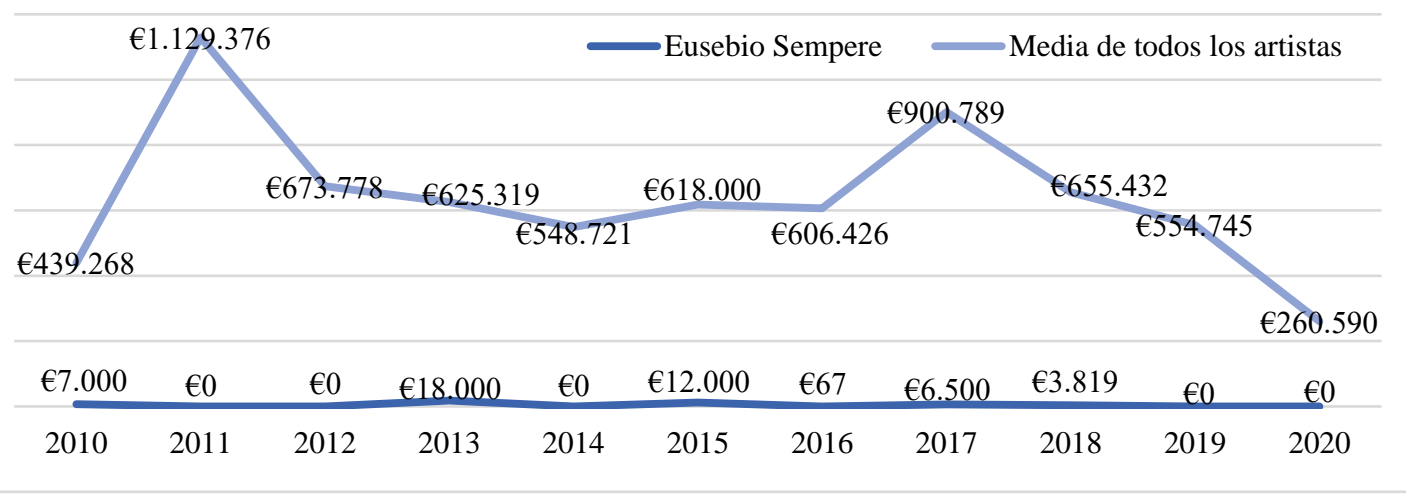

Fuente: Artprice (2020).

\section{| Notas biográficas |}

Olga Robledano Menéndez es historiadora del arte por la Universidad Complutense de Madrid (2019) y en 2020 terminó sus estudios del Máster en Gestión en Mercado del Arte de la Universidad Rey Juan Carlos. Ha realizado prácticas en diversas empresas del sector como Subastas Segre y la galería de arte NoguerasBlanchard, además de en las ferias de arte de Feriarte y ARCO. Actualmente se encuentra estudiando oposiciones al Cuerpo Facultativo de Conservadores de Museos, al tiempo que colabora en el proyecto digital compartido entre IFEMA y la URJC “Ars Feriae: Digitalización de ferias de arte" para Feriarte 365 y Antik Pasión Almoneda 365.

Ana Vico Belmonte es profesora Contratada Doctora en la Universidad Rey Juan Carlos, Doctora en Marketing (2010) y en Historia (2015), Miembro de la Real Academia de la Historia y directora del Máster Universitario en Gestión del Mercado del Arte. Sus investigaciones se centran en el ámbito de la Numismática, Mercado del Arte, Gestión Cultural y Turismo Cultural sobre los que ha escrito más de un centenar de publicaciones. Ha participado en varios proyectos de investigación nacionales e internacionales, imparte clase en másteres oficiales de diferentes Universidades al tiempo que ha participado en congresos nacionales e internacionales. Actualmente dirige el proyecto compartido entre IFEMA y la URJC “Ars Feriae: Digitalización de ferias de arte” para Feriarte 365 y Antik Pasión Almoneda 365. 